\title{
Fabrication of feeding plate to an infant with Pierre-Robin syndrome: a case report
}

\author{
Bhargavi Challagondla1, Papala Sesha Reddy², , Soundarya Kurakalva1 \\ ${ }^{1}$ Postgraduate Student, ${ }^{2}$ Assistant Professor, Department of Prosthodontics, Government Dental College \\ and Hospital, Kadapa, Andhra Pradesh, India.
}

I N F O R M A T I O N

\section{Article History}

Received 14th December 2020

Accepted 26th January 2021

Available online

$22^{\text {nd }}$ February 2021

\section{K E Y W O R D S}

Cleft-lip

Cleft Palate

Feeding plate

Pierre-Robin Syndrome
Cleft lip and palate is a congenital deformity associated with maxillary sagittal and transverse discrepancies. Feeding is an immediate concern in children born with a cleft as it delays their normal growth. A feeding plate is essential for proper nutrition, and it has a role in craniofacial development and decreases the incidence of otitis media and nasopharyngeal infections. This case report describes a single visit technique for fabrication of feeding prosthesis for a 5- day old newborn infant with cleft lip and palate. The prosthesis helps in reducing the flow of food into the nasopharynx, thus decreasing the incidence of Otis media and oronasopharyngeal infections.

\section{Introduction}

Cleft lip and palate (CLP) is the most common congenital facial anomaly. According to epidemiologic studies, its incidence varies but is usually between 1 and 1.82 for every 1000 births [1,2]. Cleft lip and palate is a congenital deformity associated with maxillary sagittal and transverse discrepancies $[1,3,4]$. In addition to skeletal discrepancies, this deformity is often accompanied by dental abnormalities, such as hypodontia, hyperdontia, and transpositions $[1,5,6]$. Cleft lip and palate may or may not be associated with various syndromes such as Pierre-Robin syndrome, Stickler's syndrome, Di George syndrome, Treacher Collins malformation, trisomy 13 and 18, Apert's syndrome, and Waardenburg's syndrome $[7,8]$.

Cleft palate is associated with difficulty in sucking, nasal regurgitation while feeding, deficiency of facial growth, dental and aesthetic problems, velopharyngeal inadequacy resulting in speech and hearing impairment and psychological problems [9]. Among all the problems, feeding is an immediate concern in children born with a cleft. Difficulty in feeding in those infants with a cleft may result in growth abnormalities. This can also be a significant concern for infants who will be undergoing surgery to correct their cleft. Cleft lip or Cleft palate can be managed by reconstructive surgery performed in the first few months after birth for Cleft lip and before 18 months for Cleft palate. Therefore, a feeding plate (FP) was recommended to the patient to overcome the problems of feeding. FP acts as a rigid platform against which the child can press the nipple to extract the milk $[7,10,11]$. A feeding plate is important for proper nutrition, and it has a role in craniofacial growth and decreases the incidence of otitis media and nasopharyngeal infections [12-14]. 


\section{Case Report}

The patient was five days old female patient with a cleft palate who weighed $2.5 \mathrm{~kg}$. The baby was referred by the Department of Paediatrics to the Department of Prosthodontics and Crown \&Bridge, Government Dental College and Hospital, Kadapa, for the fabrication of a feeding plate. On examination, it was found that the child is having Pierre-Robin syndrome with underdeveloped ears and retrognathism and cleft palate (Figure 1). After a complete examination of the patient, it was decided to fabricate a feeding plate for the patient to reduce the feeding problem.

\section{Procedure}

The preliminary impression of the maxillary arch was made with vinyl polysiloxane putty material (Adsil Putty, prime ltd) with the help of an impression tray made of self-cure acrylic resin (DPI cold cure acrylic) to hold the impression material (Figure 2). The infant was held upright by the mother to prevent the aspiration of impression material. The putty addition silicone was adapted until the impression material adequately covered the anatomy of the upper gum pads. Once the impression material was set, the putty tray was removed, and the mouth was examined for residual impression material. Beading was done around the impression with plaster of Paris and boxing was done with boxing wax. The impression was then poured with Type IV dental stone to obtain an accurate cast (Figure 3). All the undercuts were blocked out with plaster of Paris. The feeding plate was made up of an adapted vacuum-formed thermoplastic sheet.

The suturing thread was attached to the feeding appliance because it prevents swallowing and easy retrieval of the appliance (Figure 4). The appliance was placed in the child's oral cavity (Figure 5), and the final adjustment was made until the child feels comfortable with the appliance (Figure 6). Instructions were given to the parents to keep the plate in place during feeding and take out. Also, instructed to clean the appliance after feeding. Initially, it may take longer to feed the child with the plate, and even it is uncomfortable for the child, gradually it should be adjusted.
Cleft lip \& palate runs in families and predilection for some races have also been documented. Cleft lip and palate is present approximately 1 in 750 live births, $0.133 \%$. The male child has two times more predilection for Cleft lip \& palate compared to female [15-17].

According to literature, there are various ways by which the problem of feeding may be tackled, i.e. (a) Specially designed nipples with wide openings that can increase the ejection of milk with reduced effort. (b) Orogastric or nasogastric tubes may be used but for a limited length of time. (c) Presurgical infant maxillary Orthopedics (PIMO) may prove beneficial to the surgeon if a better alignment and closer approximation of the cleft segments is achieved before the actual surgical repair. (d) Surgery may close the communication, but it may not prove beneficial in all cases, especially when the separation between the cleft segments is large (e) palatal obturator that is a definite help to the feeding of an infant $[15,17]$. Obturator can also help in speech and language development, but unfortunately, little work has been done in this area [15].

Treatment of Cleft lip \& palate is a teamwork of the pediatrician, plastic surgeon, pedodontist, and prosthodontist. Cleft lip and Cleft palate are successfully treated by plastic and reconstructive surgery. However, till the surgery, to overcome the problems associated with the feeding and to restore the weight required for surgery, a temporary appliance known as Feeding plate is fabricated by the pedodontist or prosthodontist to break the vicious cycle of low weight due to which the patient becomes unfit for surgery [7].

Making an impression is the first and foremost challenging clinical step in Cleft palate infants because of lack of cooperation on behalf of the patient. The oral cavity is very small to be adequate for commercially available impression trays, with a risk of swallowing and aspiration of impression material or even being lodged in the undercuts of the defect $[12,18,19]$. Hence, it is crucial to take care of the proper positioning of the infant, a tray used and the impression material in order to maintain airway patency during impression making [12]. The feeding plate was inserted on the same day considering high anxiety of the baby's mother regarding the decreased weight of the infant relative to his age. The average weight gain of the infant indicated the proper function of the feeding plate [12]. 

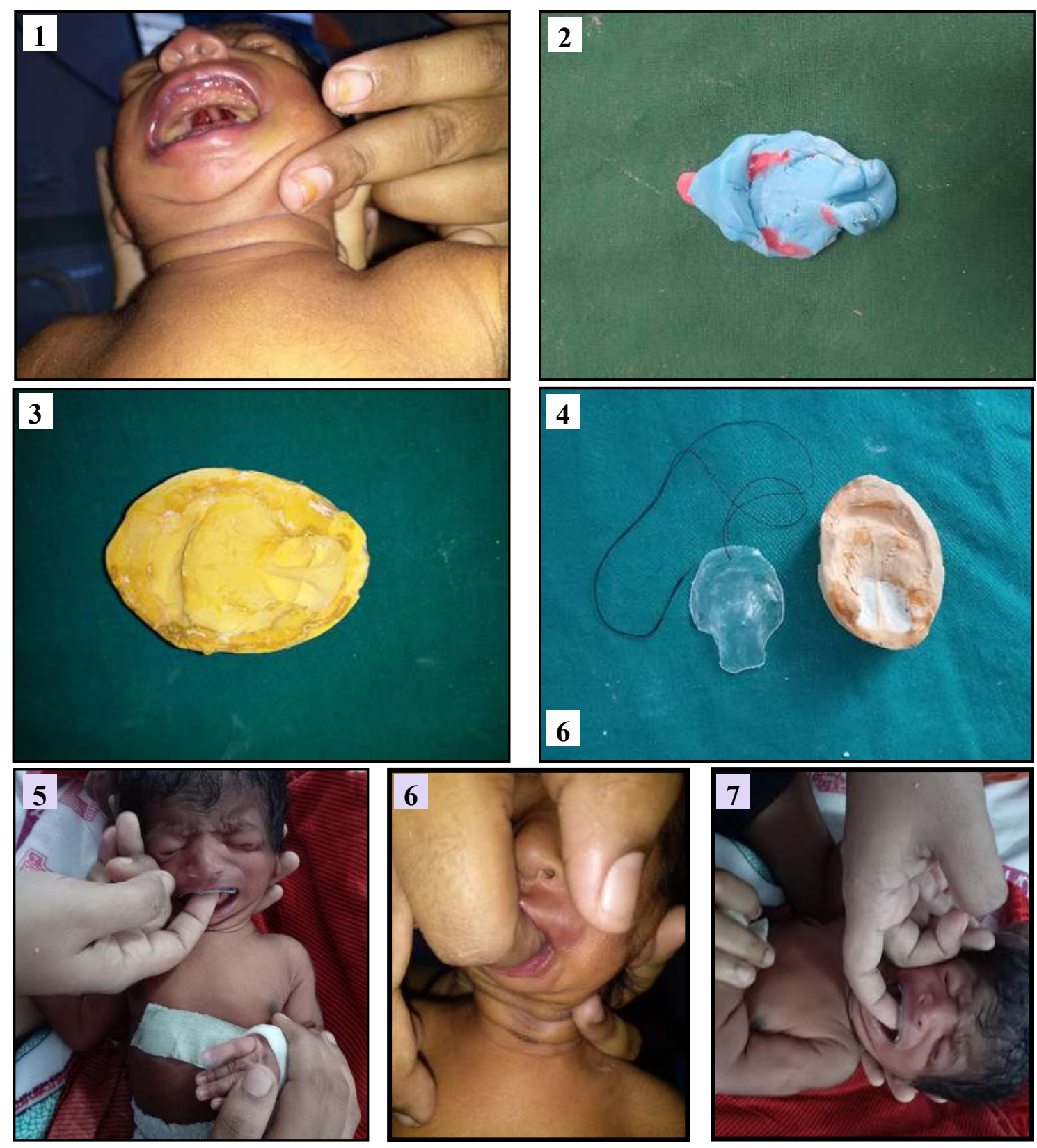

Figure 1. Baby having cleft palate.

Figures 2-6. Fabrication of feeding plate, where 2. impression of maxillary arch with cleft using custom tray and putty, 3. Maxillary master cast with cleft plate, 4. Feeding plate fabricated with thermoplastic sheet , 5. Feeding plate insertion, 6. Happily sucking baby, and 7. Follow-up after 2 months.

\section{Conclusion}

The Feeding plate overcomes the hindrances that occur during the normal growth and development of a cleft patient and should be advised as early as possible after birth. It acts as an essential tool for feeding, oral-facial development, palatal shelves development, prevention of tongue distortion, nasal regurgitation and nasal septum irritation, and avoiding ear infections. Also, it prevents the expansion of the anterior part of the maxilla, which helps the surgeon provide proper reconstructive treatment.
Conflict of interest: Authors declare no conflicts of interest.

\section{Financial Support: None}

\section{References}

1. Ambarkova V, Djipunova B, Batra M, Trajkova S. Oral Rehabilitation of patient with Cleft Lip and Palate - a case report. J Dent Probl Solut. 2017;4(4):061065. https://doi.org/10.17352/2394-8418.000051

2. Derijcke A, Eerens A, Carels C. The incidence of oral clefts: a review. $\mathrm{Br} \mathrm{J}$ Oral Maxillofacial Surg. 1996;34:488-494. 
https://doi.org/10.1016/S0266-4356(96)90242-9

3. Baek SH, Moon HS, Yang WS. Cleft type and Angle's classification of malocclusion in Korean cleft patients. Eur J Orthod. 2002; 24: 647-653.

https://doi.org/10.1093/ejo/24.6.647

4. Vettore MV, Sousa Campos AE. Malocclusion characteristics of patients with cleft lip and/or palate. Eur J Orthod. 2011; 33: 311-317.

https://doi.org/10.1093/ejo/cjq078

5. Tereza GP, Carrara CF, Costa B. Tooth abnormalities of number and position in the permanent dentition of patients with complete bilateral cleft lip and palate. Cleft Palate Craniofac J. 2010; 47: 247-252. https://doi.org/10.1597/08-268.1

6. Akcam MO, Evirgen S, Uslu O, Memikoglu UT. Dental anomalies in individuals with cleft lip and/or palate. Eur J Orthod. 2011; 32: 207-213. https://doi.org/10.1093/ejo/cjp156

7. Tulsi G, Surendra Kumar B. Fabrication of Feeding Plate in Cleft Palate Patient: A Case Report. Dent J Adv Stud 2019;7:35-37. https://doi.org/10.1055/s-0039-1684106

8. Chandna P, Adlakha VK, Singh N. Feeding obturator appliance for an infant with cleft lip and palate. J Indian Soc PedodPrev Dent 2011;29(1):71-73. https://doi.org/10.4103/0970-4388.79950

9. Rathee M, Hooda A, Tamarkar A, Yadav S. Role of feeding plate in cleft palate: case report and review of literature. Internet J Otorhinolaryngol. 2010;12:1. https://doi.org/10.5580/13a0

10. Oxford Concise Medical Dictionary. 8th ed. Oxford University Press:2010:208.

11. Kogo M, Okada G, Ishii S, Shikata M, Iida S, Matsuya T. Breast feeding for cleft lip and palate patients, using the Hotz-type plate. Cleft Palate Craniofac J. 1997;34(4):351-353. https://doi.org/10.1597/1545$1569 \_1997 \_034 \_0350 \_$bffcla_2.3.co_2

12. Amro M, Abdullah K. A single - visit feeding plate for a 3- month- old infant with cleft palate: A case report. J Dent Res Dent Prospect. 2017;11(4):253256.

13. Duarte, G.A., R.B. Ramos, and M.C. Cardoso, Feeding methods for children with cleft lip and/or palate: a systematic review. Braz J Otorhinolaryngol, 2016; 82 (5):602-9. https://doi.org/10.1016/j.bjorl.2015.10.020

14. Kumari A. Fabrication of feeding plate prosthesis for a six days old neonate: a case report. Int $\mathrm{J}$ Dent Mater. 2019;1(3):89-92.

https://doi.org/10.37983/IJDM.2019.1304

15. Rajesh B, Pathak A,Baldev B. Rehabilitation of a One -day-Old Neonate with Cleft Lipp and Palate using Palatal Obturator: A Case Report. Inter J Clin Pedia Dent. 2012;5(2):145-147.

https://doi.org/10.5005/jp-journals-10005-1154
16. Sesgin MJ, Stark RB. The incidence of congenital defects. Plast Reconstr Surg Transplant Bull. 1961; 27: 261-267.

https://doi.org/10.1097/00006534-196103000-00003

17. Green JC, Vermillion JR, Hay S, Gibbens SF, KerschbaumS. Epidemiologic study of cleft lip and palate in four states. J Am Dent Assoc. 1964;68:386404.

https://doi.org/10.14219/jada.archive.1964.0079

18. Jones SD, Drake DJ. Case series of undetected intranasal impression material in patients with clefts. $\mathrm{Br}$ J Oral Maxillofac Surg, 2013; 51(3):34-6.

https://doi.org/10.1016/j.bjoms.2011.11.015

19. Reichert F, Amrhein P, Uhlemann F. Unnoticed aspiration of palate plate impression material in a neonate: Diagnosis, therapy, outcome. Pediatr Pulmonol, 2017; 52(10):E58-60.

https://doi.org/10.1002/ppul.23710 